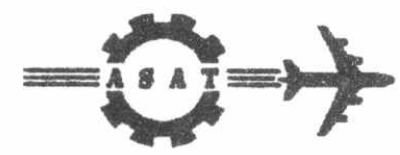

$7^{\text {th }}$ INTERNATIONAL CONF. ON AEROSPACE SCIENCES \& AVIATION TECHNOLOGY

\title{
MERGING OF REMOTE SENSING SATELLITE IMAGES
}

\author{
M. Ali Gomaa ${ }^{*}$ Fawzy El Tohamy ${ }^{* *}$ Adel Farid Abdel - Kader ${ }^{* * * *}$ \\ M. Abd El Haliem
}

\begin{abstract}
Assessment and monitoring of urban areas for development requires high resolution tools to meet the needs of urban managers and decision makers . Available high resolution satellite data, such as Russian (KVR-1000), Landsat ( TM ) and SPOT ( HVR-2 ) could provide adequate information that meet these needs .
\end{abstract}

The objective of this paper is to examine the value of merging these high resolution satellite data to discriminate urban features in Cairo city. The merging of KVR-1000 image ( 5 m resolution ) from 1991 with TM multispectral data ( $30 \mathrm{~m}$ resolution ) from 1993 is examined. Also, the merging process is carried out for the KVR-1000 image with SPOT data ( $20 \mathrm{~m}$ resolution ) from 1986 . This type of merged data can be used effectively for periodical updating of urban maps. Merging of these types of data improves the interpretation and identification of urban features. The results for a site in Cairo city is dissussed. Generally, the merged high resolution KVR-1000 and SPOT on one hand and KVR-1000 and TM on the other hand, based on visual interpretation, gives very useful tool to discremenating and mapping various urban agglomeration, such as described in Nancy urban ecosystem agglomeration scheme .

* Master Degree in systems \& computers, **Dr., M.T.C. ,Department of AVC Elec. Equip. , *** Dr. , Department of Geology , Faculty of Science ,Mansoura University. **** Prof.El-Azhar University, Department of Systems \& Computers. 


\section{INTRODUCTION}

The structure of urban land-use in developing countries is inherently complex. Residential, commercial and industrial land-use frequently are not readily seperable, and it requires high resolution data for discrimination. The currently available resolution of 5 to $10 \mathrm{~m}$ is needed for urban studies especially when monitoring area of rapid urban development .

High resolution satellite data have great potential for providing cost-effective and up-to-date information on cities in developing coutries, and also are necessary for urban mapping, due to the great accuracy needed for this type of application.

The highest resolution satellite data available to this study is the Russian data which is provided in the panchromatic band with a spatial resolution of $5 \mathrm{~m}$. In the very near future, new civil missions with higher spatial resolution close to 1 or $2 \mathrm{~m}$ will be available. This will be even better to answer the needed of accuracy for urban mapping .

The objective of this paper is to examine the value of high resolution satellite data and their fusion in monitoring urban growth and land -use /land cover changes as a means for discrimination of urban features.

The merging process is presented. An example of merging a KVR -1000 image ( spatial resolution $5 \mathrm{~m}$ ) acquired in 1991 with a more recent TM multispectral image acquired in 1993 ( resolutuin $30 \mathrm{~m}$ ) is explained. Also, the merging process is carried out for the KVR-1000 image with a SPOT image acquired in 1986 ( resolution $20 \mathrm{~m}$ ). The benefits of using this process are discused .

The merging of high resolution satellite data has been discussed earlier by several authers . Ranchin and Wald ( 1993 ) have presented some possibility of using the wavelet transforms in the field of remote sensing [1]. For a more mathematical introduction, one can refer for example to Rioul and Vetterli (1991) [2], Meyer (1993) [3]. Ranchin and Wald (1995) makes use of wavelet transform and the multiresolution analysis for merging SPOT-P and KVR-1000 images [4] . Lenco, Cour and Tourneux (1993) presented urban ecosystems planification in 50 headings of Nancy urban ecosystem [5]. Zsilincsar and Sulzer made an evaluation of remote sensing data according to their applicability for standard characteristisc of the local area [6]. Abdel-Kader, et al ( 1992 ) highlighted the use of Landsat data to monitoring urban growth and landcover changes in Greater Cairo [7] . 


\section{STUDY AREA}

The study area is a subset of Cairo city for which the available data are :

- a SPOT multispectral image acquired in 1986 with spatial resolution $20 \mathrm{~m}$, - a KVR-1000 panchromatic image acquired in 1991 with spatial resolution $5 \mathrm{~m}$, - a TM multispectral image acquired in 1993 with spatial resolution $30 \mathrm{~m}$, and, - a map for the same area ( scale 1:10,000), produced in 1995 .

These raw images are rectified by the aid of ERDAS IMAGINE software [8], and a digitizer tablet. The TM image is rectified by using the map. Then, this rectified TM image is used to rectify KVR-1000 and SPOT images .

The map coordinates for the study area are :

Upper Lift X-coordinate ( ULX) $=331003.00$;

Upper Lift Y-coordinate ( ULy) $=3336490.00$;

Lower Right X-coordinate ( LRX ) $=348813.00$; and,

Lower Right $\mathrm{Y}$ - coordinate $(\mathrm{LRy})=3315750.00$

\section{MERGING METHOD}

Landsat TM sensors have six bands ( 1-5 and 7 ). with a spatial resolution $30 \mathrm{~m}$. SPOT multispectral has three bands with a spatial resolution of $20 \mathrm{~m}$. KVR1000 panchromatic has one broad band with higher spatial resolution $5 \mathrm{~m}$. Combining TM image with KVR-1000 image yield a six band data with $5 \mathrm{~m}$ resolution would provide the best characteristics of both sensors. Also, the combination of SPOT image with KVR-1000 image yield a three band data with $5 \mathrm{~m}$ resolution [9]

The flowchart that illustrates the construction of the resolution merge principal components model is shown in Fig.1 [9] . 


\section{RESULTS}

The merging process is carried out from one side for the KVR-1000 image with TM image and on the other side for the KVR-1000 image with SPOT image [9]. Fig. 2 represents Nasr city area where Fig. 2-a,b,c,d,and e represents TM, SPOT, KVR-1000, the TM merged and the SPOT merged image respectively . In Fig. 2-b it is noticed that in block ( d-c ) and block (d-d) many new constructed buildings were not present in the SPOT image while they were present in the KVR image, but now they are available in the merged image shown in Fig. 2-e. Also, we can notice the very fine details in the merged images giving the possibility for visual interpretation.

The National park shown in merged image Fig. 2-e block (a-a ) was not present in SPOT image Fig. 2-b . We can notice the green parts in the National Park and the roads inside it in the merged images.

Fig. 3 represents Heliopolis area where Fig. 3-a,b,c,d, and e represents TM, SPOT, KVR-1000, theTM merged, and the SPOT merged images respectively . In this figure it is noticed that the stadium shown in the merged image ( Fig. 3-e ) was not present in SPOT image ( Fig. 3-b ). The very fine details are clearly noticable in the merged images .

Fig. 4 represents AL-Obour and Cairo stadium area where Fig. 4-a,b,c,d and e represents TM,SPOT, KVR-1000, TM merged , and SPOT merged images respectively. In the merged images we can descriminate the high buildings ( 14 buildings ) and Cairo stadium .

Generally, merged images showed clearly roads, bridges, airports, dense buildings, peculiar buildings, slums, cemeteries, and high -income housing with gardens .

The results are listed according to their rate of information contents as shown in table 1 [6], where : $1=$ very suitable, $2=$ suitable, $3=$ average, 4 - less suitable and $5=$ not suitable . 
Table 1 : Evaluation of remote sensing data according to their applicability for the standard characteristics of the local area

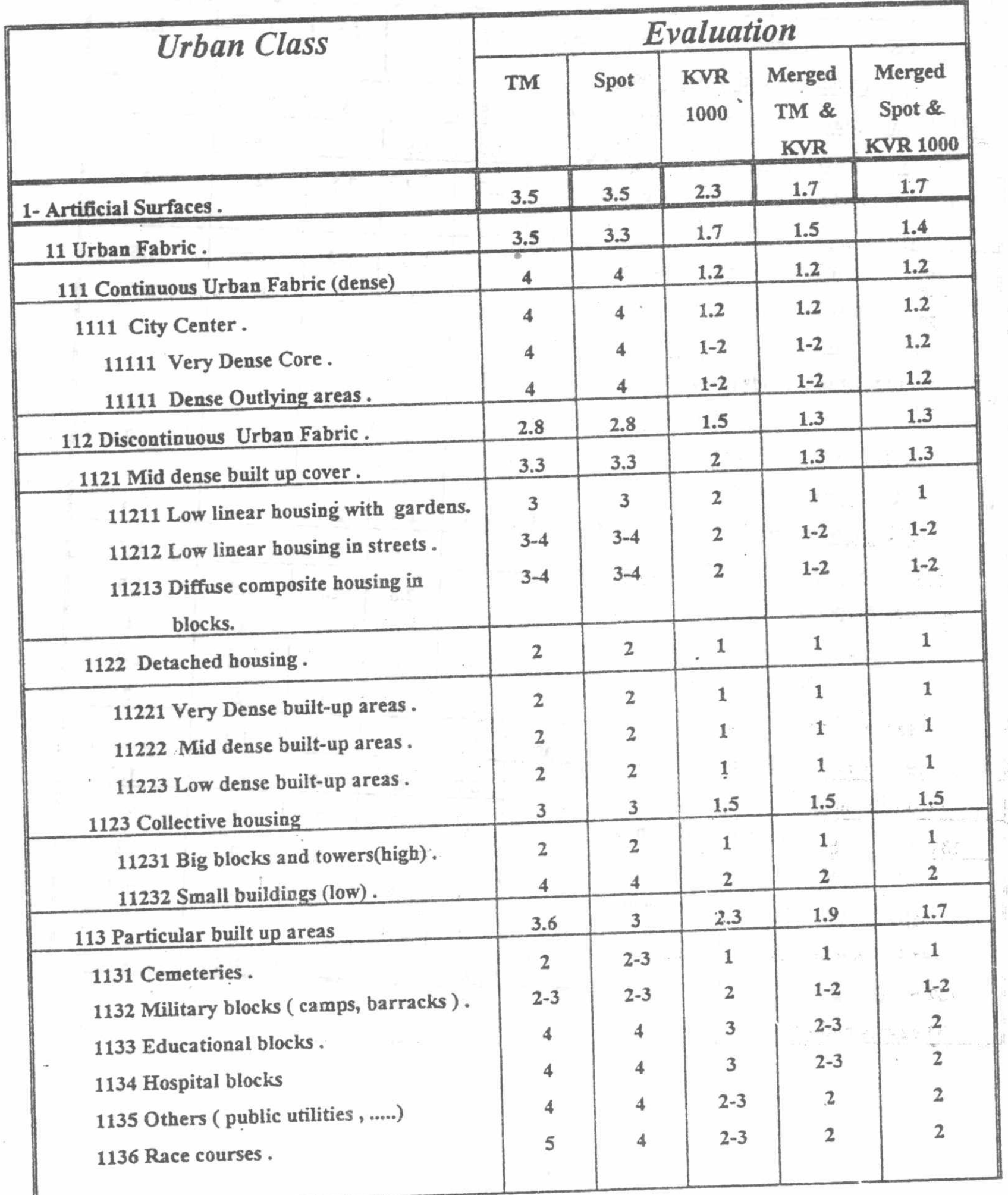


Proceedings of the $7^{\text {th }}$ ASAT Conf. 13-15 May 1997

12 Industrial, Commercial and transport units (Communication networks)

121 Industrial commercial and service units.

1211 Commercial areas (wide meaning).

122 Road and rail networks and associated

land.

1221 road network and associated land

12211 Main roads ( with vegetation inside )

12212 Main roads (without vegetation inside)

12213 Medium roads

12214 roads between houses blocks .

1222 Railway, Network and associated land

123 Airports and Airfields

1231 Airports .

12311 Civilian airports .

12312 Military airports .

1232 Air fields.

13 Artificial, non agricultural vegetated areas.

131 Green urban areas.

1311 Green area between the houses .

1312 Green area inside roads .

1313 Green area inside the parks .

132 Sport and Leisure facilities

133 castles and associated parks

\begin{tabular}{|c|c|c|c|c|}
\hline 3.7 & 3.7 & 2.5 & 2.2 & 2.2 \\
\hline 4.5 & 4.5 & 3 & 3 & 3 \\
\hline 4.5 & 4.5 & 3 & 3 & 3 \\
\hline 3.7 & 3.7 & 2.5 & 2 & 2 \\
\hline 2.8 & 2.8 & $2-3$ & 1.5 & 1.5 \\
\hline 3 & 3 & 3 & $1-2$ & $1-2$ \\
\hline 3 & 3 & 2 & $1-2$ & $1-2$ \\
\hline 2 & 2 & 2. & $1-2$ & $1-2$ \\
\hline $2-3$ & $2-3$ & 2 & $1-2$ & $1-2$ \\
\hline $4-5$ & $4-5$ & $2-3$ & $2-3$ & $2-3$ \\
\hline 2.9 & 2.9 & 1.9 & 1.7 & 1.7 \\
\hline 2.8 & 2.8 & 1.8 & 1.5 & 1.5 \\
\hline $2-3$ & $2-3$ & $1-2$ & 1 & 1 \\
\hline 3 & 3 & 2 & $1-2$ & $1-2$ \\
\hline 3 & 3 & 2 & 2 & 2 \\
\hline 3.4 & 3.4 & 2.7 & 1.4 & 1.5 \\
\hline 2.7 & 2.7 & 3.0 & 1.3 & 1.5 \\
\hline 2 & 2 & 3 & 1 & 1 \\
\hline 3 & 3 & 3 & 2 & 2 \\
\hline 3 & 3 & 3 & 1 & 1.2 \\
\hline 4 & 4 & 2 & $1-2$ & $1-2$ \\
\hline $3-4$ & $3-4$ & 3 & $1-2$ & $1-2$ \\
\hline
\end{tabular}




\section{CONCLUSION}

The merged of KVR-1000 image with SPOT image and TM image has proved a considerably enhance for the interpretation, discrimination and identification of the complex urban features of the given study area. For instance, urban and green areas are most distinguishable in the merged images..

In general, high resolution satellite data ( $5 \mathrm{~m}$ or higher) is critical for mapping urban areas and they become most useful if merged with higher spectrally sensitivily data ( such as SPOT and KVR-1000).

\section{REFFERENCES}

[1] T. Ranch and Lucien Wald. "The wavelt transeorm for the analysis of remotely sensed images ," International Journal of Remote Sensing 14,3, pp.615-619,1993.

[2] O.Rioul and M. Vetterli, "Wavelets and signal processing, "IEEE Signal Processing Magazine, vol. 8, pp. 14-38, 1991.

[3] Y. Meyer ," Wavelets Algorithms \& Applications, "Society for Industerial and Applied Mathematics (SIAM), Philadelphia, USA, 133, p.,1993.

[4] T.Ranchin and Lucien Wald " Merging SPOT-P and KVR-1000 Images for Updating Urban Maps”, The 18th Annual Symposium of the Canadian Remote Sensing Society. pp 401-404, 1995 .

[5] M. Lenco, Cour and F. Tourneux " Remote sensing from spac at 1:25,000 scale to study and watch the urban ecosystems in the built-up areas above 100,000 inhab , 25th International Symposium, Remote Sensing and Global Envionmental Change, Graz, Austria , 4-8 April 1993.

[6] W.Zsilincsar and W. Sulzer, "The application of remote sensing in local planning illustrated by the Alpine town of Schladming / Austria " 25th International Symposium, Remote Sensing and Global Envionmental Change, Graz, Austria , 4-8 April 1993.

[7] Adel-Kader, A.F. , Onsi, H.M., El-Laithy, B.M and Abdel-Hady, M.A., "Monitoring Urban and Land use Trends in the Greater Cairo Metropolitan Area using Landsat Data. XVII ISPRS Congress, Washington, DC, USA, August 1992

[8] Chris Smith \& Nicki Brown "ERDAS, Inc. ,UAS,1991.

[9] Mohamed Ali Gomaa Ph.D ,Al Azhar University, Faculty of Engineering" 1997. 


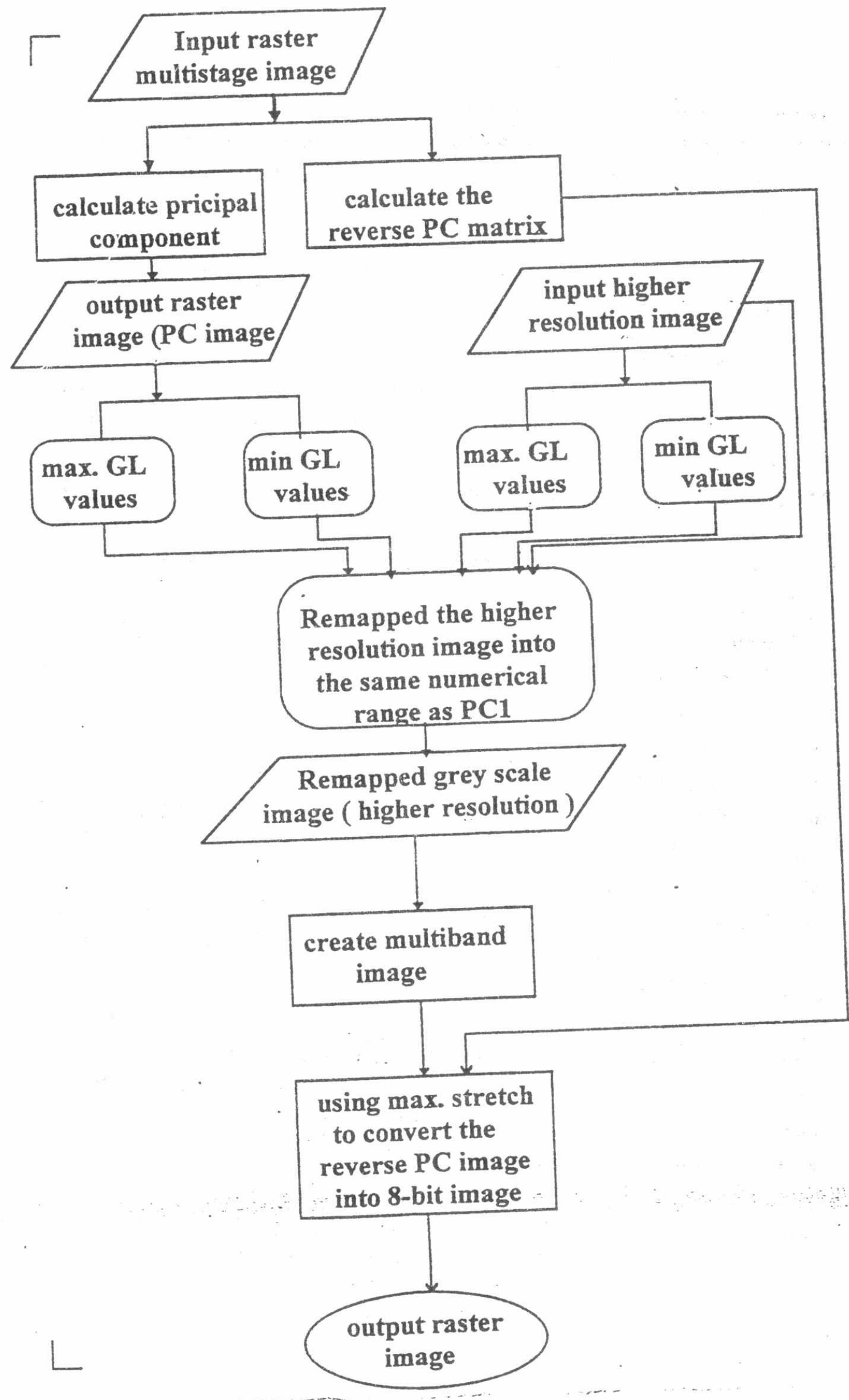

Fig. 1 The flowehart of tha racolution mawra $D F$ madnt 
(a) TM image

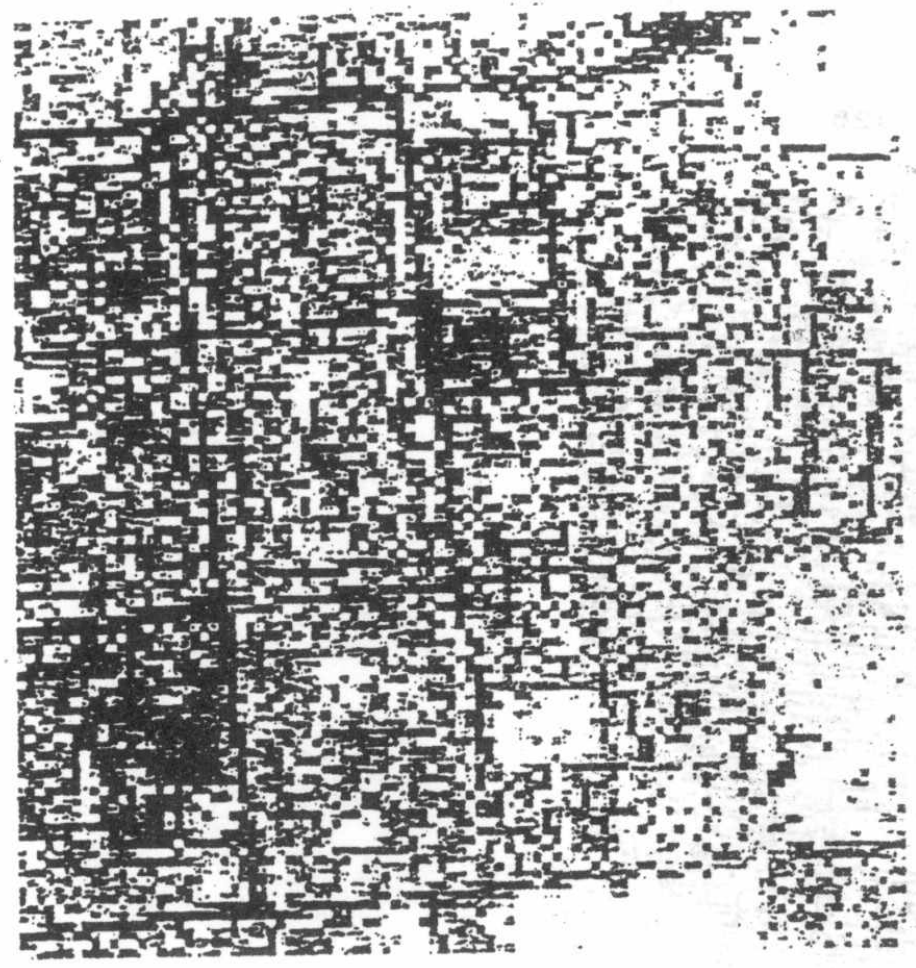

(b) SPOT image

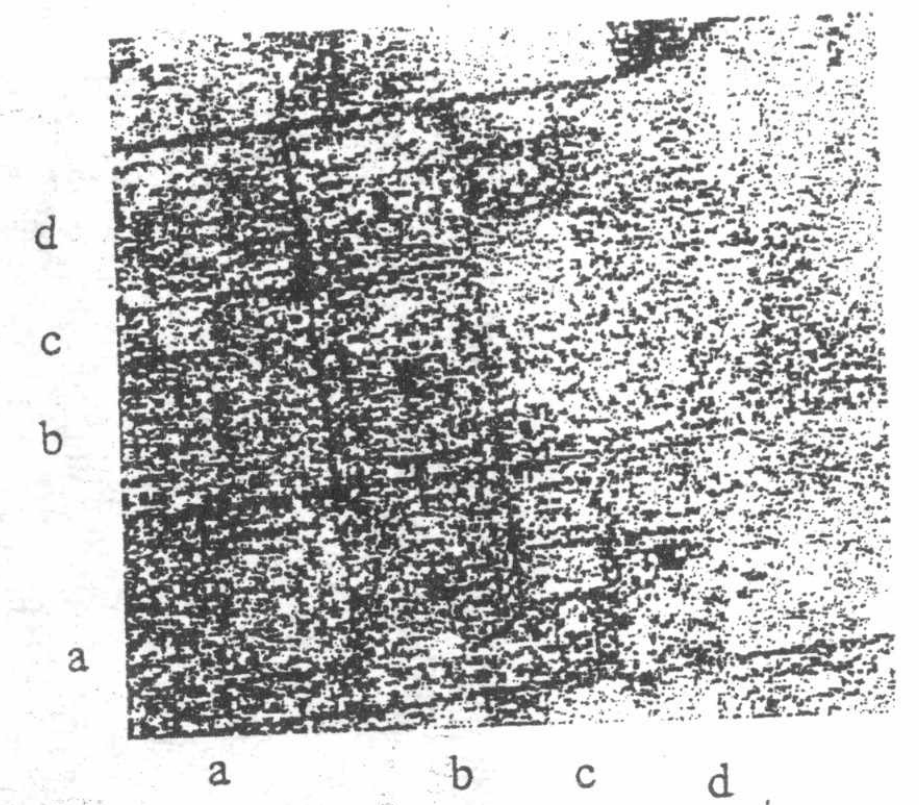

(c) KVR-1000 image

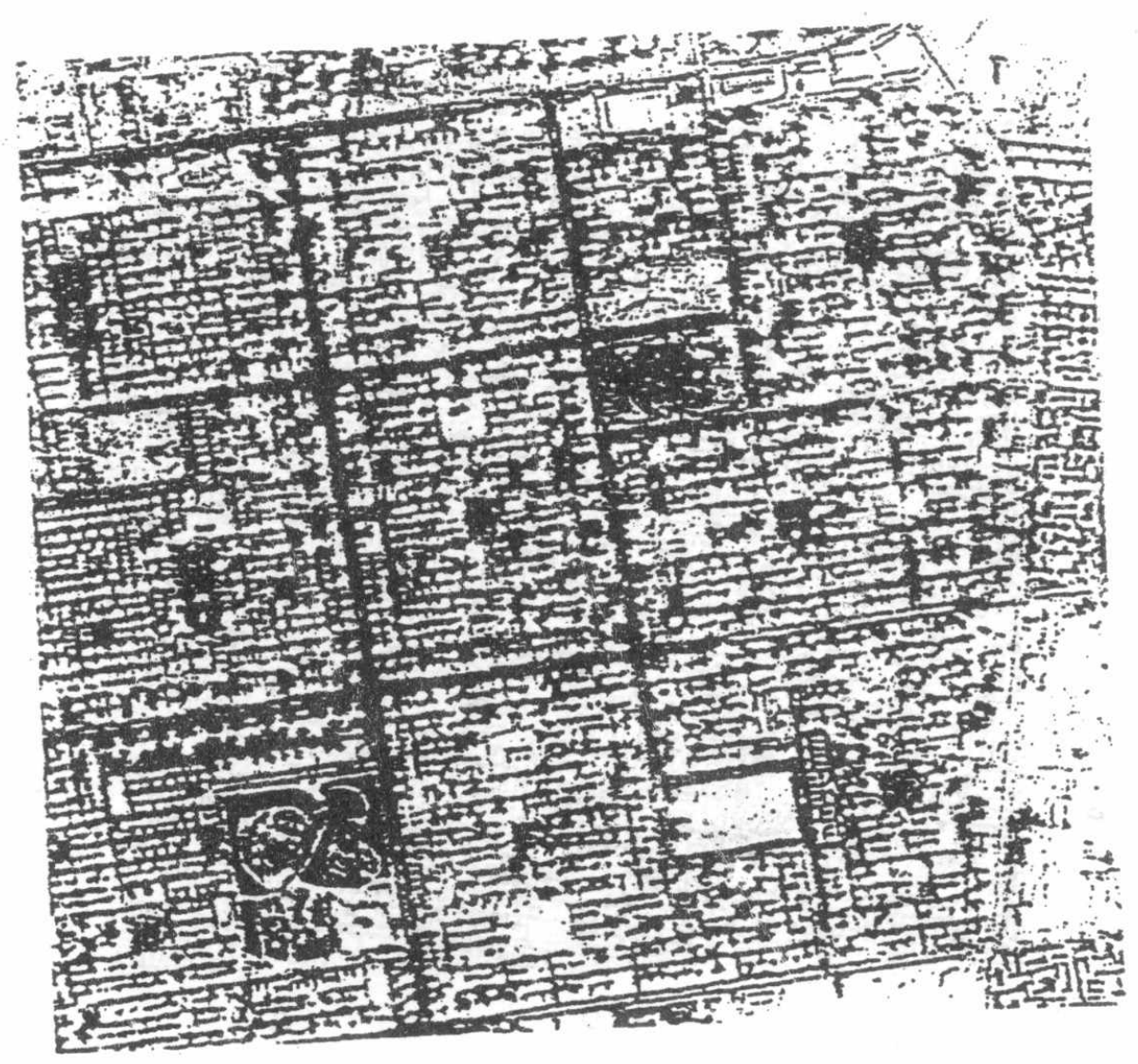

Fig. 2 Nasr city area representation . 
(d) TM merged image

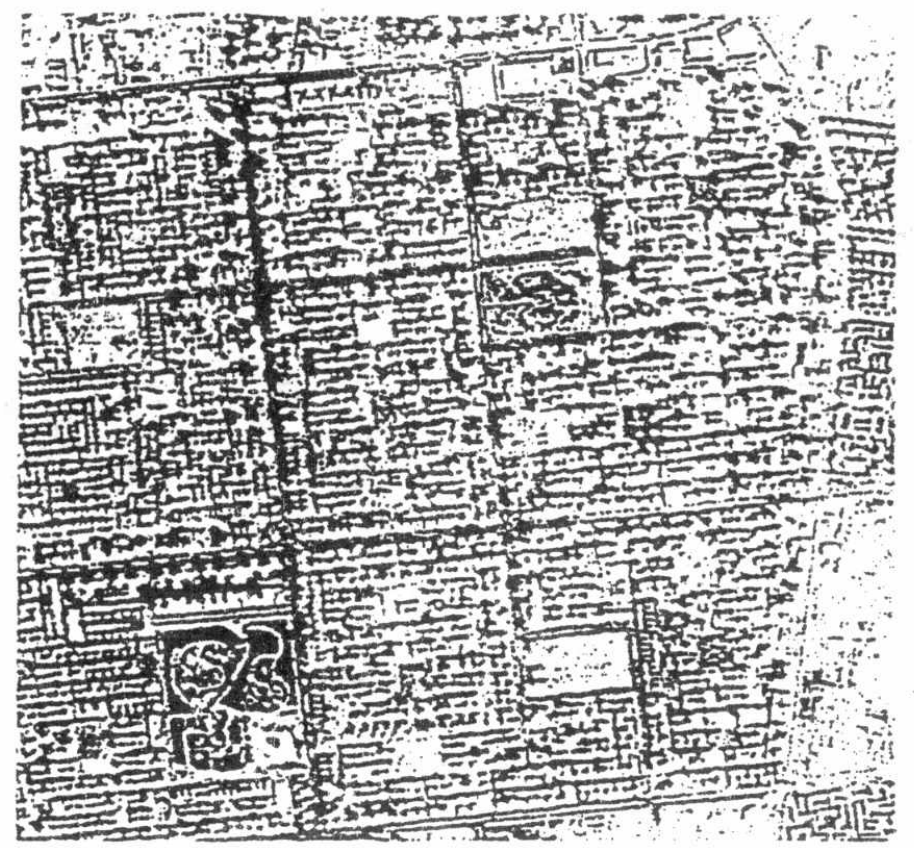

(e ) SPOT merged image

Fin

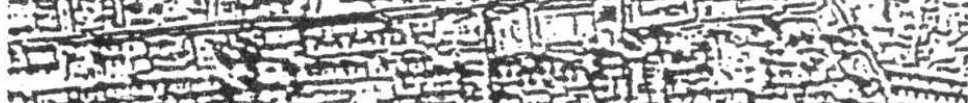
(150

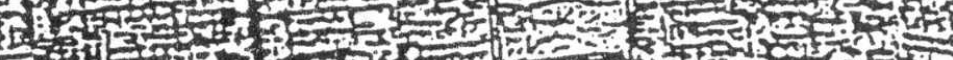
El

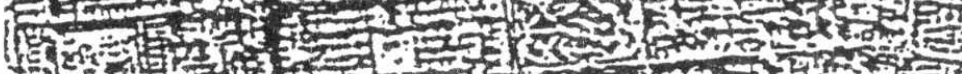

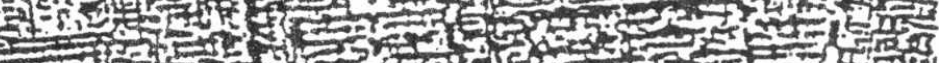
Fit 60 .

$b$

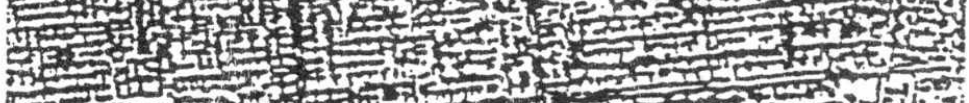
(n) (1) 
(a) TM image

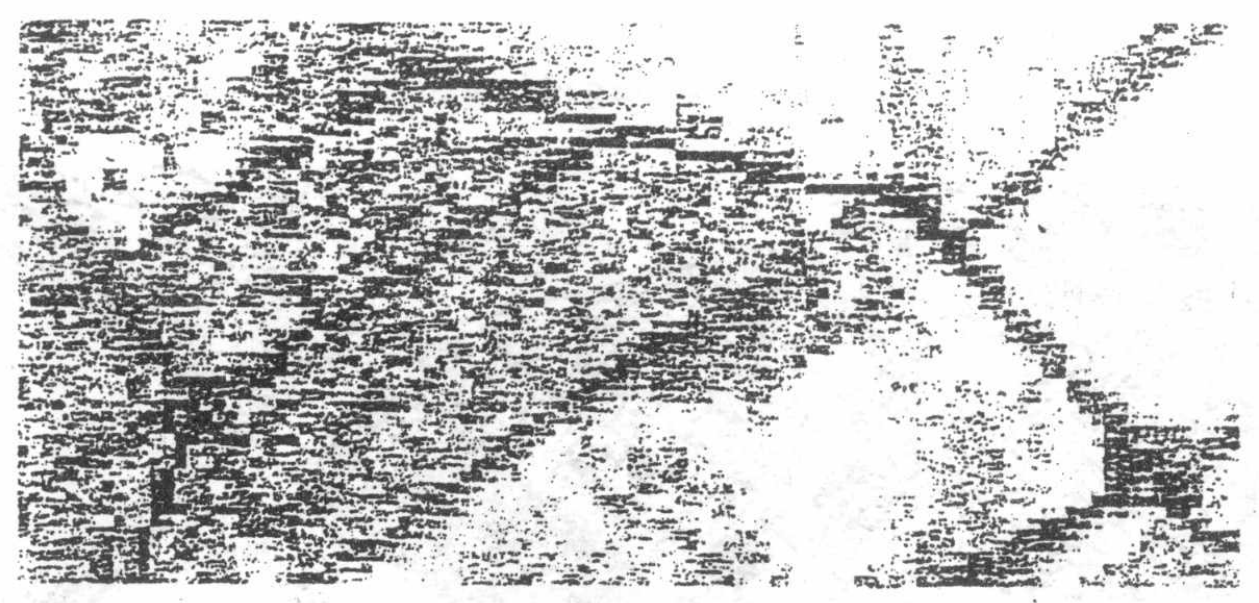

(b) SPOT image

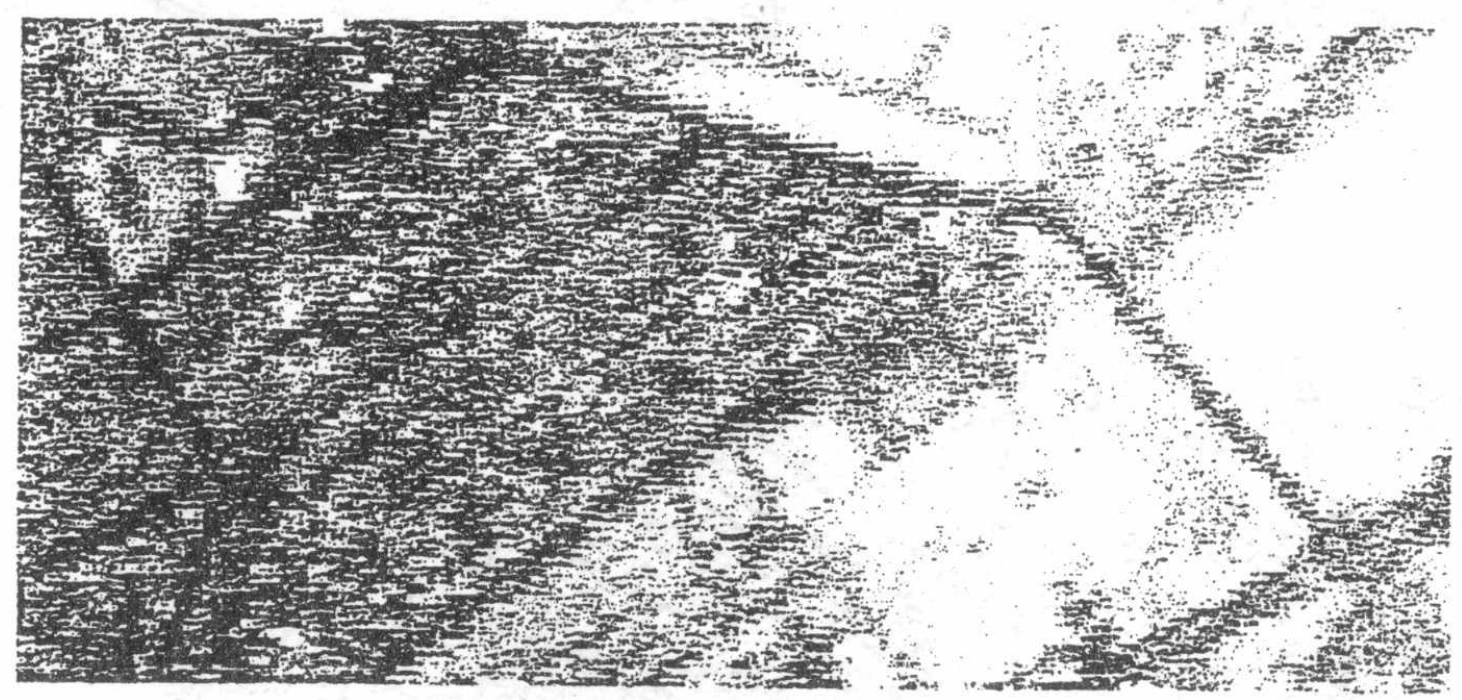

(c) KVR-1000 image

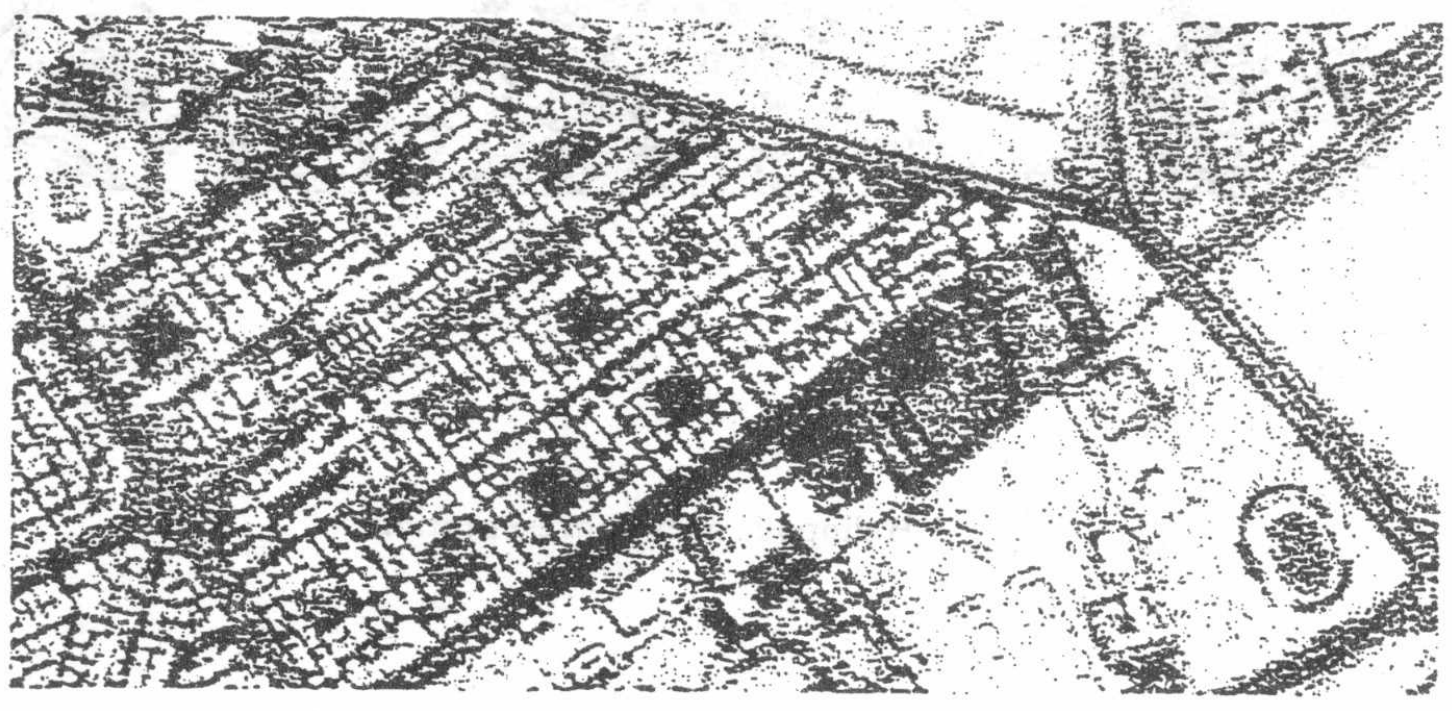

Fig. 3 Heliopolis area representation. 
(d) TM merged image

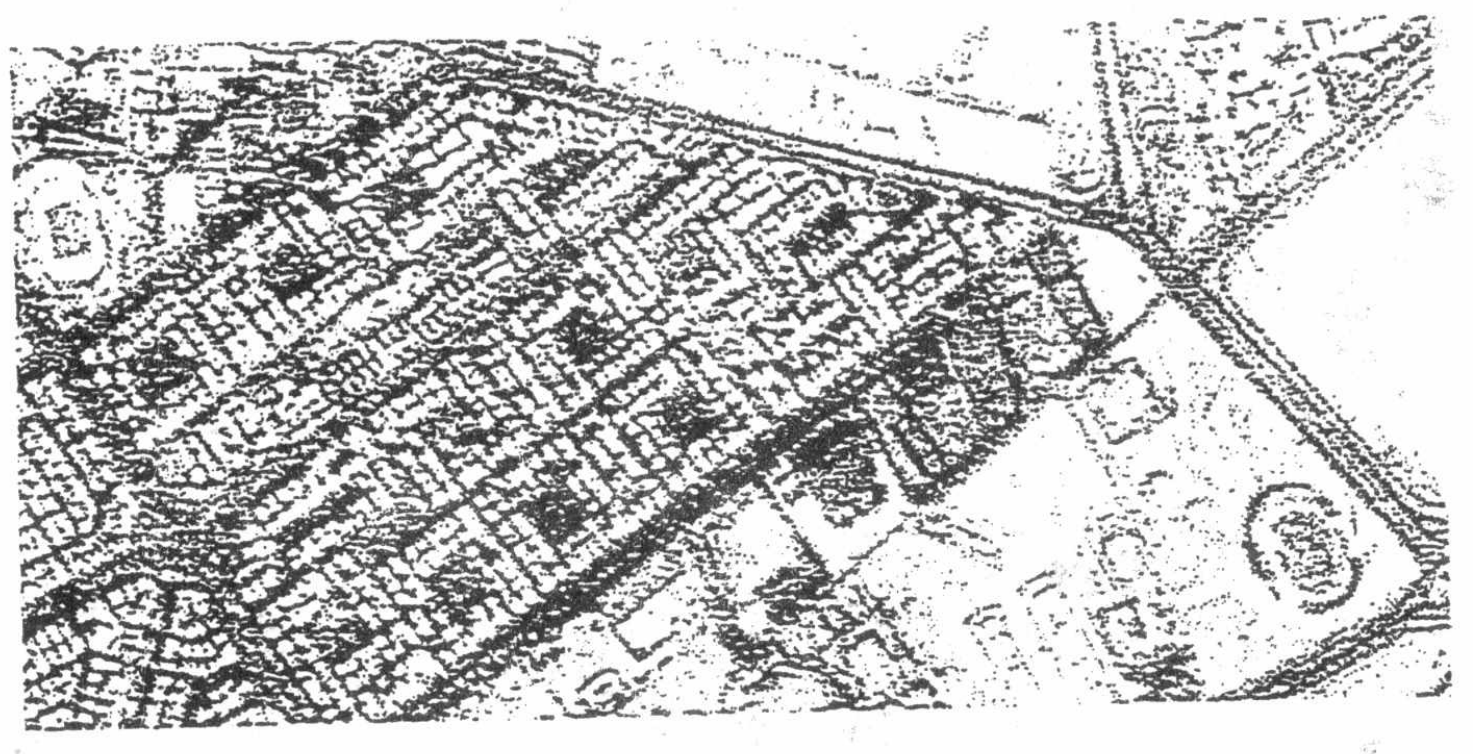

(e) SPOT merged image

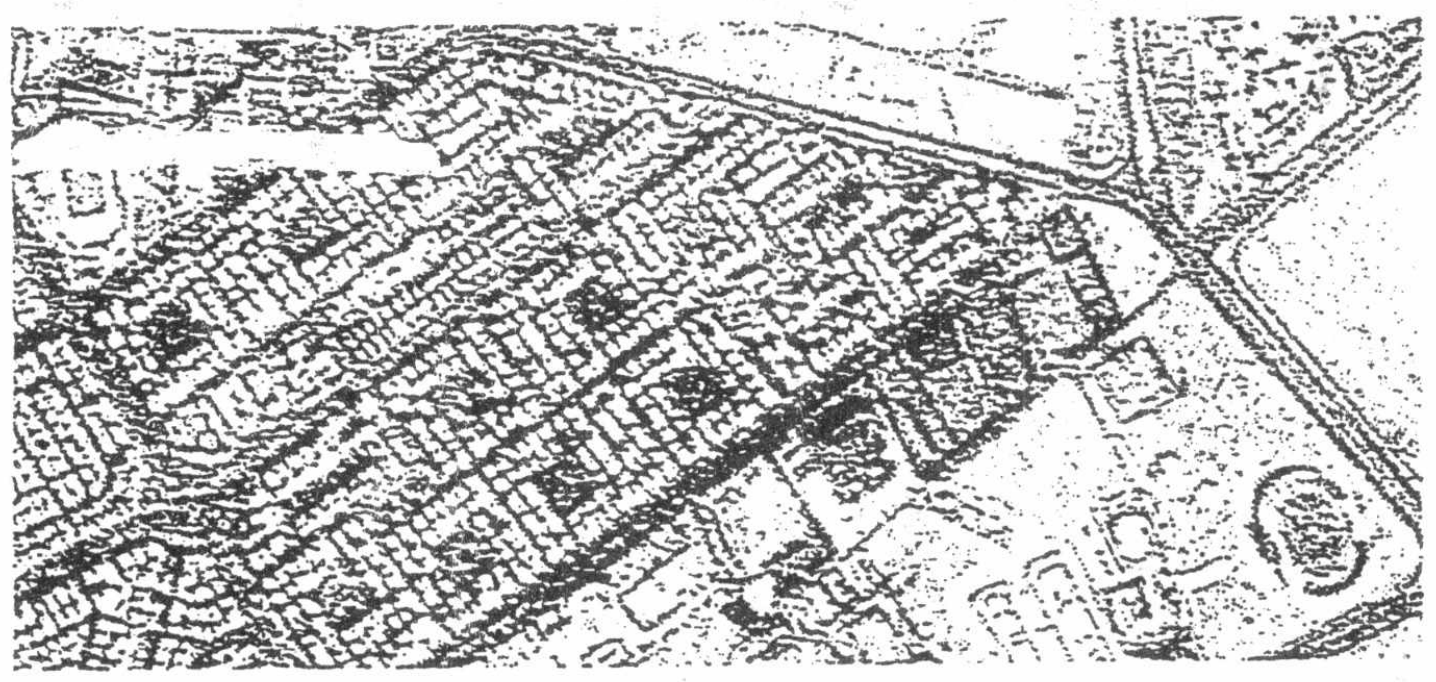

Fig. 3 Heliopolis area representation . 
(c) KVR-1000 image

(a) TM image

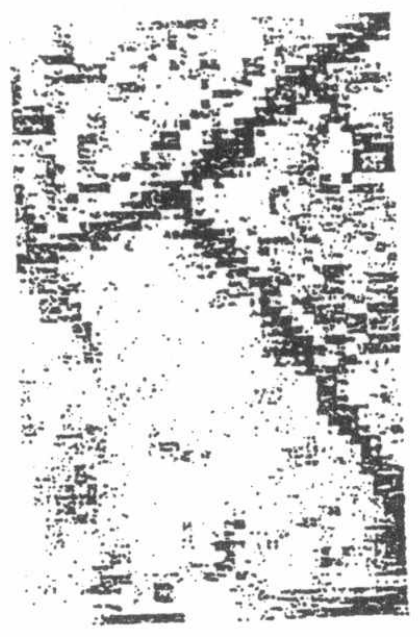

(b ) SPOT image

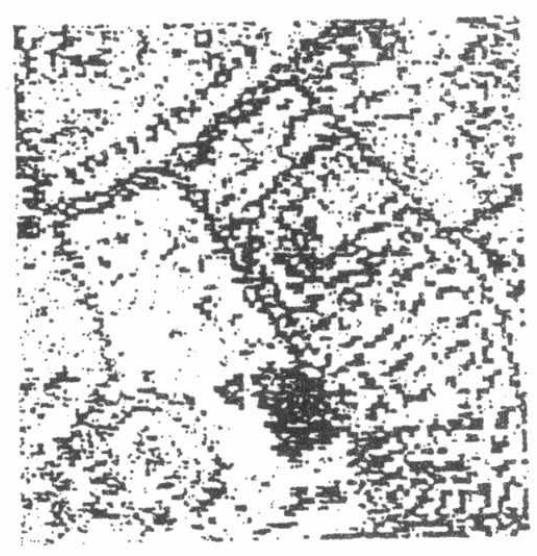

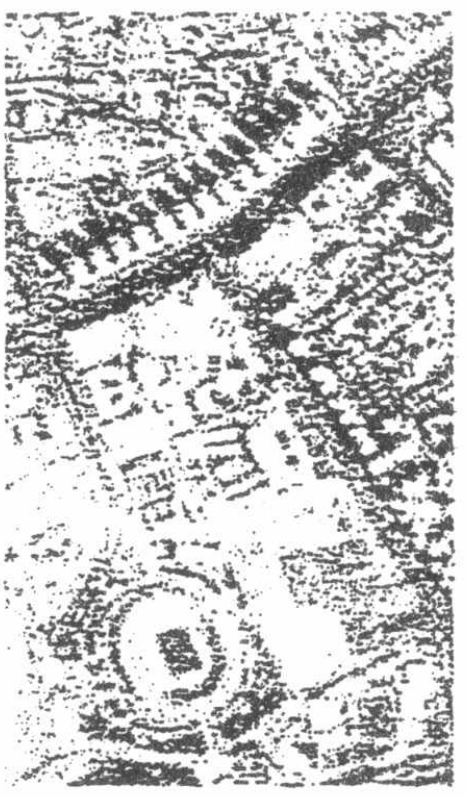

(d) TM merged image

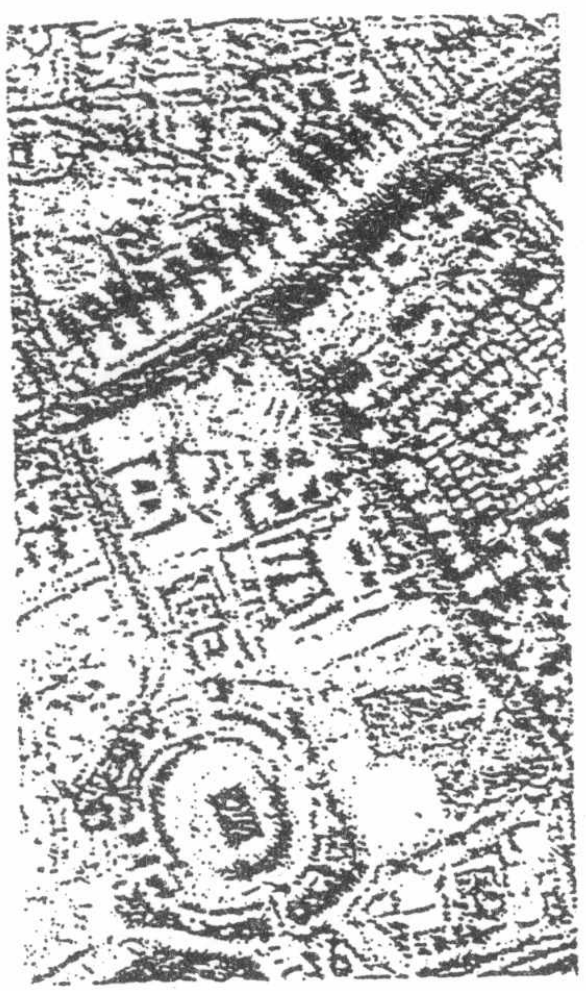

(e) SPOT merged image

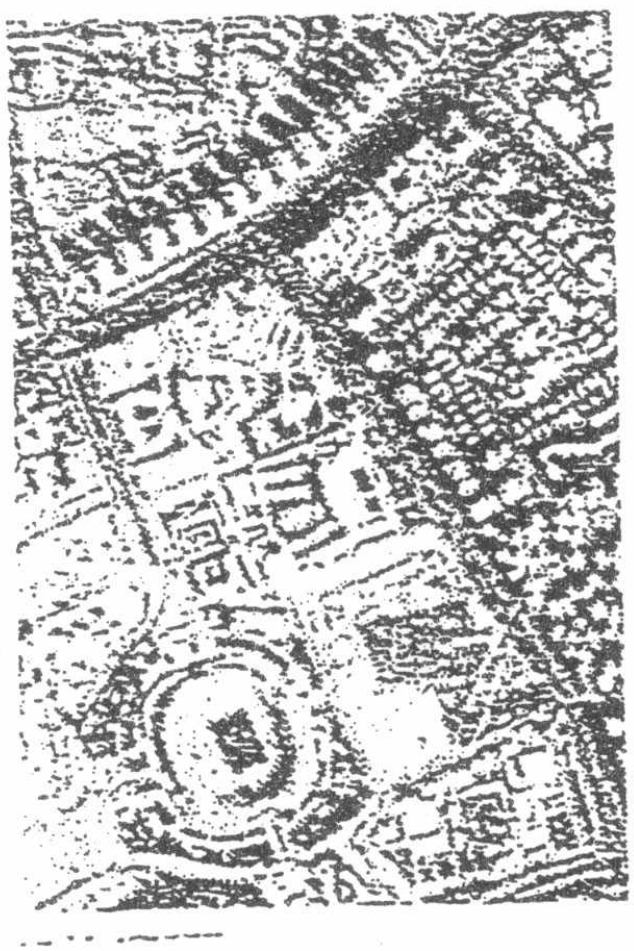

Fig. $4 \mathrm{AL}$ - Obour and Cairo stadium area representation . 